\title{
Assessing the spectrum of pulmonary hypertension identified at an Egyptian expert referral center
}

\author{
Mostafa Elshazly, Amira Ismail Mostafa* ${ }^{*}$, Asmaa Ibrahim and Irene M. Sabry
}

\begin{abstract}
Background and objective: Pulmonary hypertension is an assorted state that encompasses a spectrum of diseases and is categorized into five groups. The registries are necessary for the identification of risk factors, progression of the disease, outcomes, and effect of treatment strategies on the progression of the disease. The aim of this work was to identify different groups of PH identified at an Egyptian referral center and to compare the demographic and clinical characteristics of each group.
\end{abstract}

Patients and methods: This study included 132 patients who were diagnosed with a right heart catheter in the Chest Department, Kasr El-Aini Hospital, Faculty of Medicine, Cairo University, in the period from January 2017 to January 2019. Patients were classified into different groups, then received medical treatment accordingly. Demographic and clinical data were documented. Arterial blood gases, spirometry, and 6-minute walk test (6MWT) were performed.

Results: The mean age of cases was (43.9 \pm 13.69$)$ years; the majority of them were females (72.7\%). More than half of the patients (57.5\%) had pulmonary artery hypertension (PAH), while $22.7 \%$ and $18.3 \%$ had pulmonary hypertension due to chronic thrombo-embolic cause and lung cause respectively. The 1-year survival rate was $81.8 \%$.

Conclusions: The results of the study showed female predominance, the PAH type was the commonest, and the overall 1-year survival rate was $81.8 \%$.

Keywords: Pulmonary hypertension, Pulmonary arterial hypertension, Registry, Survival rate

\section{Background}

The definition of pulmonary hypertension $(\mathrm{PH})$ is elevated mean pulmonary artery pressure (mPAP) more than $25 \mathrm{mmHg}$ at right heart catheterization (RHC). It is classified into five different groups: group 1, pulmonary arterial hypertension (PAH); group 2, $\mathrm{PH}$ due to left heart disease (LHD); group 3, PH due to lung disease; group 4, chronic thromboembolic $\mathrm{PH}(\mathrm{CTEPH})$; and group $5, \mathrm{PH}$ with unclear multifactorial mechanisms [1].

It is a severe, progressive disease associated with significant morbidity and mortality [2]. However, it is a rare

*Correspondence: dramira755@gmail.com

Department of Chest Diseases, Faculty of Medicine, Cairo University, Cairo, Egypt disease; the registries are necessary for the identification of risk factors, progression of the disease, outcomes, and effect of treatment strategies on the progression of the disease.

For more than two decades, the National Institutes of Health $(\mathrm{NIH})$ registry has collected data on the epidemiology of the idiopathic, familial, and anorexigen-associated forms of $\mathrm{PAH}$, providing important information on survival and prognostic markers among these patients [3].

In recent years, some registries put into practice the description of the natural history of $\mathrm{PH}$, raising the awareness of that silent disease and promoting more and more options for its discovery and treatment. From that point of view; the current study brings to light the 
Egyptian experience of a single pulmonary hypertension center, identifying the demographic and clinical characteristics of different $\mathrm{PH}$ groups.

\section{Subjects and methods} Study design and population

A descriptive retrospective study was conducted in the Chest Department, Kasr El-Aini Hospital, Faculty of Medicine, Cairo University, in the period from January 2017 to January 2019. It involved 132 cases with pulmonary hypertension. Informed written consent was obtained from all participants. The ethical committee of the Faculty of Medicine, Cairo University, approved the study.

\section{Inclusion criteria}

- All patients who were diagnosed by right heart catheter (RHC) to have mean pulmonary artery pressure $(\mathrm{mPAP}) \geq 25 \mathrm{mmHg}$.

\section{Exclusion criteria}

- Patients refusing the procedure of RHC.

\section{Preparation and laboratory evaluation}

All patients were subjected to complete history tacking and clinical evaluation, the dyspnea scale according to NYHA association, complete blood picture, arterial blood gases, spirometry, and 6-minute walk test (6MWT).

\section{Radiological evaluation}

All patients underwent chest high-resolution computerized tomography (HRCT) or CT pulmonary angiography (CTPA), abdominal ultrasound, and echocardiography and ventilation/perfusion (VQ) scan.

\section{Right heart catheter}

Swan-Ganz catheter (TriOxTM PA Catheter, $8 \mathrm{~F}, 110 \mathrm{~cm}$, J-tip, Heparin coated) was used. In addition to the balloon at the tip for flotation, it consists of an endhole port, a side-hole port $30 \mathrm{~cm}$ from the catheter tip. The pressure transducer was set to zero level at the mid-thoracic line with the patient in a supine position, halfway between the anterior sternum and bed surface, which represents the level of the left atrium [4].

Under visualization by ultrasound, Swan-Ganz catheter was introduced through the internal jugular vein to obtain pressure measurements in the right atrium, right ventricle, pulmonary artery, pulmonary artery wedge position. To obtain measurements of pulmonary artery wedge pressure (PAWP), the balloon was inflated in the right atrium, from where the catheter was advanced until it reaches the PAWP position [5].

Repeated inflations and deflations in the wedge position were avoided to avoid pulmonary artery rupture. Mixed venous oxygen saturation (SvO2) was measured while the tip of the catheter was in the pulmonary artery, whereas systemic oxygen saturation was acquired noninvasively by oximetry [6]. Cardiac output was calculated by the Fick method:

$$
\begin{aligned}
\text { Cardiac output }(1 / \mathrm{min})= & \text { oxygen consumption }(\mathrm{ml} / \mathrm{min}) \\
& /\left(\Delta \mathrm{A}-\mathrm{V} \mathrm{O}_{2} \times 1.36 \times \text { Hemoglobin }(\mathrm{mg} / \mathrm{dL}) \times 10\right)
\end{aligned}
$$

where $\Delta \mathrm{A}-\mathrm{V} \mathrm{O}_{2}$ is the arterial-venous oxygen saturation difference and the constant 1.36 is the oxygen-carrying capacity of hemoglobin (expressed in $\mathrm{mL} \mathrm{O}_{2} / \mathrm{g} \mathrm{Hgb}$ ). In addition to the evaluation of cardiac output, the cardiac index was calculated as the ratio of cardiac output to body surface area. Pulmonary vascular resistance (PVR) was calculated as: $\mathrm{PVR}=\mathrm{mPAP}-$ mean $\mathrm{PAWP}) /$ cardiac output [7]. Pulmonary vascular resistance index (PVRI) was calculated as the ratio of PVR to body surface area.

\section{Statistical analysis}

All statistical calculations were done using computer programs Microsoft Excel 2003 (Microsoft Corporation, NY, USA) and SPSS version 17 statistical program (Statistical Package for the Social Science; SPSS Inc., Chicago, IL, USA). A probability value ( $p$ value) less than 0.05 was considered statistically significant.

All comparisons between two groups were performed using Student's $t$ test. $P$ value $<0.05$ was considered statistically significant.

\section{Results}

\section{Patient's characteristics}

This study included 132 patients diagnosed by RHC as having pulmonary hypertension, most of them were females $(72.7 \%)$. The mean age was $43.9 \pm 13.69$ years (Table 1). The youngest patients were present in groups 2 and 3 PHT, hence the mean age in these two groups was 28 and 33 years respectively.

\section{Clinical and laboratory evaluation in different groups}

In the current study; the most common group was $\mathrm{PAH}$ (57.5\%, $n=76)$, followed by CTEPH $(22.7 \%, n=30)$, group $3(18.3 \%, n=24)$, then group $2 \mathrm{PH}$ due to left ventricular dysfunction $(1.5 \%, n=2)$ (Table 1$)$. The mean distance in performing $6 \mathrm{MWT}$ was $209 \pm 120 \mathrm{~m}$. The majority of cases presented by grade III of dyspnea $(60.6 \%, n=80)$, 
Table 1 Patients' characteristics $(n=132)$

\begin{tabular}{ll}
\hline Age (years) & $43.9 \pm 13.69$ \\
Sex distribution & \\
Female & $96(72.7 \%)$ \\
Male & $36(27.3 \%)$ \\
PHT groups & \\
Group 1 & $76(57.5 \%)$ \\
Group 2 & $2(1.5 \%)$ \\
Group 3 & $24(18.3 \%)$ \\
Group 4 & $30(22.7 \%)$ \\
Females & \\
Group 1 & $74 \%$ \\
Group 2 & $100 \%$ \\
Group 3 & $83 \%$ \\
Group 4 & $60 \%$ \\
Age (years) & \\
Group 1 & 42.5 \\
Group 2 & 33 \\
Group 3 & 23 \\
Group 4 & 42 \\
\hline
\end{tabular}

Continuous data expressed as mean \pm standard deviation

PHT pulmonary hypertension

and the rest of them were grades II and IV $(28.7 \%, n=38$ and $10.7 \%, n=14$, respectively) (Table 2 ).

\section{General and hemodynamic characteristics in PAH} and CTEPH groups and its correlation with survival

The hemodynamic parameters of the two biggest groups are summarized in (Table 3 ).

Mean 6MWT distance was $209 \mathrm{~m} \pm 120 \mathrm{~m}$. After 1 year, the mean distance was $244 \mathrm{~m} \pm 127 \mathrm{~m}$.

After 1 year follow-up, the overall survival rate in all cases was $81.8 \%$. All patients $(n=2)$ in group 2 were still alive, while survival in groups 1,3 , and 4 was $89.4 \%$, $66.6 \%$, and $73.3 \%$, respectively (Table 4 ). The present study found the mean age of survivors to be $42.4 \pm 14.3$ years in PAH and $40.2 \pm 9.8$ years in CTEPH, while in the non-survivors, it was $40.7 \pm 12.5$ years in $\mathrm{PAH}$ $(p>0.05)$ and $47 \pm 20.7$ years in CTEPH $(p>0.05)$. Moreover, in $\mathrm{PAH}$, the mean $6 \mathrm{MWT}$ distance in survivors was

Table 2 Patients' clinical evaluation $(n=132)$

\begin{tabular}{ll}
\hline NYHA score & \\
II & $38(28.7 \%)$ \\
III & $80(60.6 \%)$ \\
IV & $14(10.7 \%)$ \\
6MWD (meters) & $209 \pm 120$ \\
\hline
\end{tabular}

Continuous data expressed as mean \pm standard deviation

6MWD 6-minute walk distance
Table 3 Hemodynamic parameters of PAH and CTEPH groups

\begin{tabular}{lll}
\hline & PAH $(\boldsymbol{n}=\mathbf{7 6})$ & CTEPH $(\boldsymbol{n}=\mathbf{3 0})$ \\
\hline sRAP & $13.1 \pm 5.5$ & $15.6 \pm 7$ \\
dRAP & $3.6 \pm 3.9$ & $5.07 \pm 4$ \\
mRAP & $7.5 \pm 5$ & $9.93 \pm 5.5$ \\
sRVP & $85.8 \pm 23$ & $81.6 \pm 27$ \\
dRVP & $3.2 \pm 4$ & $2.4 \pm 3.1$ \\
mRVP & $38.2 \pm 12$ & $33.2 \pm 16.8$ \\
mPAP & $54.29 \pm 14.2$ & $50.13 \pm 11$ \\
PAWP & $8.3 \pm 2.5$ & $7.87 \pm 3.48$ \\
SvO $\%$ & $60.25 \pm 12.3$ & $61 \pm 12.7$ \\
CO & $4.34 \pm 2$ & $4.47 \pm 1.68$ \\
CI & $2.37 \pm 1$ & $2.37 \pm 0.8$ \\
PVR & $13.1 \pm 8$ & $9.3 \pm 4.37$ \\
PVRI & $7.6 \pm 5.5$ & $4.89 \pm 2.3$ \\
\hline
\end{tabular}

Pressures in $\mathrm{mmHg}$. CO in liters/minute. $\mathrm{Cl}$ in liters/minute/meter ${ }^{2}$. PVR in Wood units. PVRI in Wood units.meter ${ }^{2}$

Continuous data expressed as mean \pm standard deviation

$P A H$ pulmonary arterial hypertension, CTEPH chronic thrombo-embolic pulmonary hypertension, $S R A P$ systolic right atrial pressure, $d R A P$ diastolic right atrial pressure, $m R A P$ mean right atrial pressure, $s R V P$ systolic right ventricular pressure, $d R V P$ diastolic right ventricular pressure, $m R V P$ mean right ventricular pressure, MPAP mean pulmonary artery pressure, PAWP pulmonary artery wedge pressure, $\mathrm{SvO}_{2}$ systemic mixed venous oxygen saturation, $\mathrm{CO}$ cardiac output, $\mathrm{Cl}$ cardiac index, $P V R$ pulmonary vascular resistance, $P V R I$ pulmonary vascular resistance index

$232.9 \pm 113.6 \mathrm{~m}$ while it was $131.2 \pm 123 \mathrm{~m}$ in non-survivors $(p>0.05)$. On the other hand, the mean 6MWT distance in survivors with CTEPH was $238.5 \pm 100.5 \mathrm{~m}$ while it was $141 \pm 128.4 \mathrm{~m}$ in non-survivors $(p>0.05)$. Hence, there was an insignificant role of age and $6 \mathrm{MWT}$ in predicting the survival in each group.

Moreover, considering the relation between survival and patients' hemodynamic parameters, we found no statistically significant differences $(p>0.05)$ between survivors and non-survivors (Table 5).

\section{Discussion}

Pulmonary hypertension is defined as an increase in mean pulmonary arterial pressure (mPAP) $\geq 25 \mathrm{mmHg}$ at rest as assessed by right heart catheterization (RHC) [8]. Although $5 \mathrm{PH}$ groups are recognized, the majority of studies in $\mathrm{PH}$ have focused on $\mathrm{PAH}$ and $\mathrm{CTEPH}$. The aim

Table 4 Survival rate in 1-year follow-up

\begin{tabular}{lll}
\hline PHT groups & Survival & Mortality \\
\hline Group 1 & $89.4 \%$ & $10.6 \%$ \\
Group 2 & $100 \%$ & $0 \%$ \\
Group 3 & $66.6 \%$ & $33.4 \%$ \\
Group 4 & $73.3 \%$ & $26.7 \%$ \\
\hline
\end{tabular}

PHT pulmonary hypertension 
Table 5 Comparison between survivors and non-survivors of PAH and CTEPH groups

\begin{tabular}{|c|c|c|c|c|c|c|}
\hline \multirow[t]{2}{*}{ Parameter } & \multicolumn{3}{|l|}{ PAH $(n=76)$} & \multicolumn{3}{|c|}{ CTEPH $(n=30)$} \\
\hline & Survivors & Non-survivors & $p$ & Survivors & Non-survivors & $p$ \\
\hline Age & $42.4 \pm 14.3$ & $40.7 \pm 12.5$ & 0.81 & $40.2 \pm 9.8$ & $47 \pm 20.7$ & 0.46 \\
\hline 6MWD & $232.9 \pm 113.6$ & $131.2 \pm 123$ & 0.116 & $238.5 \pm 100.5$ & $141 \pm 128.4$ & 0.139 \\
\hline mPAP & $54.35 \pm 14.7$ & $53.75 \pm 10.6$ & 0.962 & $50.1 \pm 11.39$ & $50.2 \pm 13.2$ & 0.951 \\
\hline mRAP & $6.9 \pm 4.6$ & $12.5 \pm 6.9$ & 0.73 & $8.8 \pm 5.1$ & $12.2 \pm 6.3$ & 0.21 \\
\hline mRVP & $38 \pm 12.4$ & $40.2 \pm 11.4$ & 0.739 & $30.5 \pm 19.5$ & $38.6 \pm 8.6$ & 0.42 \\
\hline PAWP & $8.15 \pm 2.4$ & $9.7 \pm 3.5$ & 0.278 & $9.2 \pm 2.9$ & $5.2 \pm 3.1$ & 0.054 \\
\hline $\mathrm{SvO}_{2} \%$ & $60.05 \pm 12.2$ & $62 \pm 15.2$ & 0.66 & $63.9 \pm 11.5$ & $55.2 \pm 14.5$ & 0.32 \\
\hline $\mathrm{Cl}$ & $2.32 \pm 1.04$ & $2.9 \pm 0.4$ & 0.08 & $2.4 \pm 0.8$ & $2.3 \pm 1.03$ & 0.53 \\
\hline PVR & $13.7 \pm 8.2$ & $7.9 \pm 2.7$ & 0.199 & $8.9 \pm 5.1$ & $9.9 \pm 3.06$ & 0.94 \\
\hline
\end{tabular}

Age in years. Distance in meters. Pressures in $\mathrm{mmHg} . \mathrm{Cl}$ in liters/minute/meter ${ }^{2}$. PVRI in Wood units.meter ${ }^{2}$

Continuous data expressed as mean \pm standard deviation

$P A H$ pulmonary arterial hypertension, CTEPH chronic thrombo-embolic pulmonary hypertension, 6MWD 6-minute walk distance, $m P A P$ mean pulmonary artery pressure, $m R A P$ mean right atrial pressure, $m R V P$ mean right ventricular pressure, $P A W P$ pulmonary artery wedge pressure, $\mathrm{S}_{\mathrm{O}} \mathrm{O}_{2}$ systemic mixed venous oxygen saturation, $\mathrm{Cl}$ cardiac index, $P V R$ pulmonary vascular resistance

of this study was to identify different groups of $\mathrm{PH}$ and assess the survival among its different groups.

As mentioned before, the most common group was PAH $(57.5 \%, n=76)$, followed by CTEPH $(22.7 \%, n=30)$, then group $3(18.3 \%, n=24)$. The least cases were those of group $2 \mathrm{PH}$ due to left ventricular dysfunction (1.5\%, $n=2$ ) because those patients are usually diagnosed and managed by cardiologists and are not referred to our center. Group 1 (PAH) had a lower share than in COMPERA (Comparative, Prospective Registry of Newly Initiated Therapies for Pulmonary Hypertension), a prospective European registry in 28 centers in 6 countries, in which $71 \%$ of all patients had PAH and $29 \%$ had nonPAH-PH [8]. On the other hand, in ASPIRE registry that enrolled 1344 patients, the commonest group was $\mathrm{PAH}$ (49.62\%), followed by CTEPH (20\%), group 3 (14.7\%), group 2 (12.98\%), and the least common was group 5 (2.6\%) [9].

Furthermore, the Giessen Pulmonary Hypertension Registry enrolled 2067 patients; $33.1 \%$ had PAH, $14.9 \%$ had $\mathrm{PH}$ due to left heart disease, $26.4 \%$ had $\mathrm{PH}$ due to lung disease, $22.2 \%$ had CTEPH, and $3.4 \%$ had group 5 PH [10]. The percentage of PAH in this study was higher than those of ASPIRE registry and Giessen registry, but lower than that of COMPERA, which may be due to different sample sizes in each study.

Female predominance was reported in the current work; $72.7 \%$ of the cases were females while $27.3 \%$ were males. That came in accordance with ASPIRE registry, in which female predominance of $62 \%$ was also reported [9]. Moreover, in the Giessen Pulmonary Hypertension Registry, the female percentage was $58.94 \%$ with a female-tomale ratio of 1.24:1 [10].
In the same line, the National Registry evaluating the characterization of Primary Pulmonary Hypertension (US-NIH) which enrolled 187 PAH patients from 32 centers, women were more frequently affected, with a female predominance of 63\% [3]. Another French registry enrolled 674 PAH cases; females were 65\% [11]. In addition, REVEAL registry showed marked female predominance $(80 \%$ of $\mathrm{PAH})$ [12]. There was a female predominance in all registries of $\mathrm{PAH}$, and this can be explained by the role for hormonal influences (particularly estrogen) in the pathogenesis of PAH, as estrogen may promote cellular proliferation [13].

Considering the age of patients with $\mathrm{PH}$, the mean age of all patients in this study was $43 \pm 13.69$ years which was lower than that of ASPIRE registry and Giessen registry, in which the mean age at diagnosis was $59 \pm 17$ years and 59.6 years respectively $[9,10]$. In the same line, French and REVEAL registries reported higher age of patients, with a mean age of $50 \pm 15$ years and $53 \pm 14$ years, respectively $[11,12]$.

On the other hand; the mean age of PAH was lower than the current study, as it was $36 \pm 15$ and $36 \pm 9$ years in US-NIH and Saudi registry respectively [3, 14]. This could be explained by different demographics and awareness.

In the present work, $28.7 \%$ of cases presented with grade II dyspnea, $60.6 \%$ with grade III dyspnea, and $10.7 \%$ with grade IV dyspnea. That came in harmony with ASPIRE and Giessen registry: dyspnea grade III counted for $65 \%$ of cases in both registries, while grade IV was $16 \%$ and $22 \%$, respectively $[9,10]$. Moreover, in the REVEAL registry, dyspnea grade III was $50 \%$ and grade IV was $5.6 \%$ [12]. These differences may be due to a 
lack of awareness and the vague symptoms of $\mathrm{PH}$, which may delay seeking medical advice.

In the present work, 1-year survival rate in all cases was $81.8 \%$. However, the ratio was different among the different groups; $89.4 \%$ in group 1, $100 \%$ in group 2, $66.6 \%$ in group 3 and $73.3 \%$ in group 4 . That came in agreement with ASPIRE registry, in which the 1-year survival rate was $88 \%$ for group 1, $90 \%$ for group 2, $65 \%$ for group 3 , $89 \%$ for group 4 , and $84 \%$ for group 5 [9].

In the Giessen registry, the 1-year survival rate was $85.5 \%$, with 1 -year survival rate of $88.2 \%$ for those with PAH, $86.7 \%$ for group 2, $79.5 \%$ for patients with group 3 , and $89.2 \%$ for group 4 [10]. Moreover, in US-NIH and French registry, the 1-year survival rate was $68 \%$ and $89.3 \%$, respectively $[3,11]$. The lower rate of survival in our study could be explained by the presence of advanced management in the developed countries rather than the developing countries and delayed seeking of medical advice in the developing countries. On the other hand, the higher rate of survival in comparison with US-NIH was attributed to the fact that that registry was in the era before the development of specific therapy.

Regarding the hemodynamics, the mean mPAP was $54.29 \pm 14.2 \mathrm{mmHg}$ in $\mathrm{PAH}$ and $50.13 \pm 11 \mathrm{mmHg}$ in CTEPH. This was similar to other registries $[9,10,12]$.

In the present study, there were insignificant roles of age and 6MWT in predicting the survival in each group, which came in contrast with the Giessen registry which stated that the age less than 50 years and 6MWT distance more than $390 \mathrm{~m}$ were predictive of survival [10].

\section{Limitations}

The present is study is limited by the small number of patients in group 2 ( $\mathrm{PH}$ due to left heart disease). However, as mentioned before, those patients are usually diagnosed and managed by cardiologists and are not routinely referred to our center.

\section{Conclusions}

We concluded that there is a female predominance in patients diagnosed with $\mathrm{PH}$, the mean age was $43.9 \pm 13.6$ years, PAH was the most common group (57.5\%) and group $2 \mathrm{PH}$ was the least common (1.5\%). Moreover, the overall 1-year survival rate was $81.8 \%$. Age, $6 \mathrm{MWT}$, and hemodynamic parameters did not have a significant role in predicting survival in our study.

\footnotetext{
Abbreviations

6MWT: 6-minute walk test; Cl: Cardiac index; CO: Cardiac output; CTEPH: Chronic thrombo-embolic pulmonary hypertension; CTPA: Computerized tomography pulmonary angiography; HRCT: High-resolution computerized tomography; LHD: Left heart disease; mPAP: Mean pulmonary artery pressure; PAH: Pulmonary arterial hypertension; PAWP: Pulmonary artery wedge
}

pressure; PH: Pulmonary hypertension; PVR: Pulmonary vascular resistance; PVRI: Pulmonary vascular resistance index; $\mathrm{RHC}$ : Right heart catheterization; $\mathrm{SvO}_{2}$ : Mixed venous oxygen saturation; $V Q$ : Ventilation/perfusion.

\section{Acknowledgements \\ Not applicable.}

\section{Authors' contributions}

ME designed the study and supervised the whole work. AIM performed data analysis and submitted the manuscript. Al collected clinical data and coordinated sample collection and statistics. IMS supervised the collection of clinical data and wrote the manuscript. All authors read and approved all of the final manuscript.

\section{Funding}

This research received no specific grant from any funding agency from commercial or not-for-profit sectors.

\section{Availability of data and materials}

The datasets generated during the current study are not publicly available due to hospital policies and because the data will be used in future research to generate a nationwide registry. However, these datasets are available from the corresponding author on reasonable request.

\section{Declarations}

\section{Ethics approval and consent to participate}

The authors assert that this work complies with the ethical standards of the relevant national guides on care and has been approved by the ethics committee of the Faculty of Medicine, Cairo University.

\section{Consent for publication}

Not applicable.

\section{Competing interests}

The authors declare that they have no competing interests.

Received: 8 September 2021 Accepted: 12 October 2021 Published online: 04 November 2021

\section{References}

1. Simonneau G, Galie N, Rubin LJ, Langleben D, Seeger W, Domenighetti G, Gibbs S, Lebrec D, Speich R, Beghetti M, Rich S (2004) Clinical classification of pulmonary hypertension. J Am Coll Cardiol 43(12 Supplement):S5-S12

2. Moreira EM, Gall H, Leening MJ, Lahousse L, Loth DW, Krijthe BP, Kiefte-de Jong JC, Brusselle GG, Hofman A, Stricker BH, Ghofrani HA, Franco OH, Felix JF (2015) Prevalence of Pulmonary Hypertension in the General Population: The Rotterdam Study. PLoS One 10(6):e0130072

3. Rich S, Dantzker DR, Ayres SM, Bergofsky EH, Brundage BH, Detre KM, Fishman AP, Goldring RM, Groves BM, Koerner SK, Levy PC (1987) Primary pulmonary hypertension: a national prospective study. Ann Intern Med 107(2):216-223

4. Kovacs G, Avian A, Pienn M, Naeije R, Olschewski H (2014) Reading pulmonary vascular pressure tracings. How to handle the problems of zero leveling and respiratory swings. Am J Respir Crit Care Med 190(3):252-257

5. Hoeper MM, Gall H, Seyfarth HJ, Halank M, Ghofrani HA, Winkler J, Golpon H, Olsson KM, Nickel N, Opitz C, Ewert R (2009) Long-term outcome with intravenous iloprost in pulmonary arterial hypertension. Eur Respir J 34(1):132-137

6. Mathier MA (2011) The nuts and bolts of interpreting hemodynamics in pulmonary hypertension associated with diastolic heart failure. Advances in Pulm Hypertens 10(1):33-40

7. Grossman W (2006) Blood flow measurement: cardiac output and vascular resistance. In: Grossman's Cardiac Catheterization, Angiography, and Intervention. Lippincott Williams \& Wilkins, Philadelphia, pp 148-162 
8. Hoeper MM, Bogaard HJ, Condliffe R, Frantz R, Khanna D, Kurzyna M, Langleben D, Manes A, Satoh T, Torres F, Wilkins MR (2013) Definitions and diagnosis of pulmonary hypertension. J Am Coll Cardiol 62(25 Supplement):D42-D50

9. Hurdman J, Condliffe R, Elliot CA, Davies C, Hill C, Wild JM, Capener D, Sephton P, Hamilton N, Armstrong IJ, Billings C (2012) ASPIRE registry: Assessing the spectrum of pulmonary hypertension identified at a referral centre. Eur Respir J 39(4):945-955

10. Gall H, Felix JF, Schneck FK, Milger K, Sommer N, Voswinckel R, Franco OH, Hofman A, Schermuly RT, Weissmann N, Grimminger F (2017) The Giessen Pulmonary Hypertension Registry: Survival in pulmonary hypertension subgroups. J Heart Lung Transplant 36(9):957-967

11. Thenappan T, Shah SJ, Rich S, Tian L, Archer SL, Gomberg-Maitland M (2010) Survival in pulmonary arterial hypertension: a reappraisal of the $\mathrm{NIH}$ risk stratification equation. Eur Respir J 35(5):1079-1087

12. McGoon MD, Krichman A, Farber HW, Barst RJ, Raskob GE, Liou TG, Miller DP, Feldkircher K, Giles S (2008) Design of the REVEAL registry for US patients with pulmonary arterial hypertension. Mayo Clin Proc 83(8):923-931

13. Wysowski DK, Golden L, Burke L (1995) Use of menopausal estrogens and medroxyprogesterone in the United States, 1982-1992. Obstet Gynecol 85(1):6-10

14. Idrees MM, Al-Najashi K, Khan A, Al-Dammas S, Al-Awwad H, Batubara E, Al Otai A, Abdulhameed J, Fayed A, Kashour T, Taskforce SR (2014) Pulmonary arterial hypertension in Saudi Arabia: Patients' clinical and physiological characteristics and hemodynamic parameters. A single center experience. Ann Thorac Med 9(4):209

\section{Publisher's Note}

Springer Nature remains neutral with regard to jurisdictional claims in published maps and institutional affiliations.

\section{Submit your manuscript to a SpringerOpen ${ }^{\odot}$ journal and benefit from:}

- Convenient online submission

- Rigorous peer review

- Open access: articles freely available online

- High visibility within the field

- Retaining the copyright to your article

Submit your next manuscript at $>$ springeropen.com 